\title{
Short Term Load Forecasting based on BPL Neural Network with Weather Factors
}

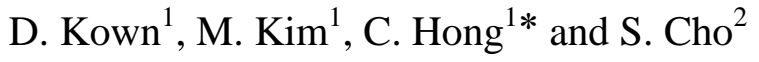 \\ ${ }^{1}$ Department of Computer Science, Sangmyung University, Seoul, Korea \\ ${ }^{2}$ Department of Energy Grid, Sangmyung University, Seoul, Korea
}

hongch@smu.ac.kr

\begin{abstract}
This paper presents the development of Short Term Load Forecasting (STLF) model using Artificial Neural Network (ANN). STLF is required for electric power planning and electricity market planning. The proposed model predicts the load demand of Connecticut in the U.S. using hourly historical electric load and weather data. For improving the load prediction accuracy, we consider two main issues that are seasons and weather factors. Each season has different load demand patterns, thus the weather facton are differently applied in each season. The proposed model uses the composited weather factor which consists of temperature and dew point. The temperature and dew point weather factors are selected through the correlation coefficient to obtain the meaningful data among the weather factors. The selected weather factors adjust the level of the pitch which is the predicted load demand of one day ahead. The propesed model improves the forecasting accuracy both in summer and winter.
\end{abstract}

Keywords: Short_Term Load Fónecasting, Artificial Neural Networks, Back propagation learning

\section{Introduction}

Load forecasting can be divided into three categories such as long-term load forecasting (LTLF), mid-term load forecasting (MTLF) and short-term forecasting (STLF). LTLF/ is necessary to manage the electric supply and demand planning which requires a lot of cost for electric facilities such as power station, power transmission, transformen, etc. STLF is required to optimize power control and scheduling such as adjusting power capacity and load switching $[1,2]$.

STLF has been widely studied using ANN approach which is an effective method for processing nonlinear data such as weather factors and historical load data. The Back Propagation Learning (BPL) is the famous learning algorithm among ANNs [3]. In order to develop the one day ahead forecasting model, we use BPL algorithm. Weather factors are the most influencing factor for load demand forecasting using BPL. In this paper, according to the result of correlation analysis, the temperature and dew point are selected as primary weather factor. Selected weather factor is used to adjust the weather weight to improve the load forecasting accuracy.

* Corresponding Author 


\section{Backpropagation Learning Algorithm}

BPL is the most commonly used method for time series prediction, pattern recognition as well as short term load forecasting. BPL algorithm aims to reduce the error between calculated value and desired output value using the gradient-decent search method [4].

Each input nodes receive input variables using the initial weight and send them to all hidden layer's nodes. At this time, the transfer function is used for sending to hidden layer. Each hidden unit computes the weight and transfers it to the output node. Output node calculates the error with desired output, and error is propagated back. Each hidden node updates the weights that were propagated back [5].

BPL is separated into two phases which are the propagation and weight update. In the Propagation phase, first, we initialize input value such as the weight and bias, The input value is conveyed to the hidden layers using equation (1),

net $_{\mathrm{pj}}=\sum_{\mathrm{n}=1}^{\mathrm{n}} \mathrm{W}_{\mathrm{ji}} \mathrm{O}_{\mathrm{pi}}+\theta$

Where, $\mathrm{j}$ is number of hidden layer, $i$ is number of input layer

$\mathrm{W}_{\mathrm{ji}}$ is the weight of the connection fropr unit $\mathrm{j}$ to anif. $\mathrm{W}_{\mathrm{ji}}$ determines the strength of the connection. $\theta$ is the bias of the hidden layer and net ${ }_{\mathrm{pj}}$ is the input value which is the sum of the weights. Next, the equation (1) transfers the result of the total weight into the next hidden layer through the log-sigmoid function (equation (2)).

$\mathrm{O}_{\mathrm{pj}}=\frac{1}{1+e^{-n e t_{p j}}}$

Next phase, we compute the weight update for the back propagation. First, the error $\mathrm{E}$ is calculate using equation (3). $\mathrm{t}_{\mathrm{pk}}$ is the desired target output values.

$\mathrm{E}=\frac{1}{2} \sum_{\mathrm{n}=\mathrm{k}}^{\mathrm{n}}\left(\mathrm{t}_{\mathrm{pk}}-\mathrm{O}_{\mathrm{pk}}\right)^{2}$

Where, $\mathrm{k}$ is number of output layer.

The error of neuron $\mathrm{k}^{\text {th }}$ is calculated by equation (4) and each hidden layer's error is calculated byequation (5).

$\delta_{\mathrm{pk}}=\left(t_{\mathrm{pk}}-O_{\mathrm{pk}}\right) O_{\mathrm{pk}}\left(1-O_{\mathrm{pk}}\right)$

$\delta_{\mathrm{pj}}=O_{\mathrm{pj}}\left(1-O_{\mathrm{pj}}\right) \sum_{k=1}^{m} \delta_{p k} W_{k j}$

$\Delta \mathrm{W}_{\mathrm{ji}}$ is used to update each hidden network weight for correcting errors. $\eta$ is the learning rate parameter and $\alpha$ is the momentum (equation (6)) [4].

$\Delta \mathrm{W}_{\mathrm{ji}}(n+1)=\eta \delta_{\mathrm{pj}} 0_{\mathrm{pi}}+\alpha \Delta \mathrm{W}_{\mathrm{ji}}(n)$ 


\section{Input Variables Selection}

Selecting Input variables is very important to apply the multilayer feed forward neural network model for forecasting the load demand [6]. There is a high correlation between load demand and three factors which are categorized as the weather factors, time factors, and economic factors. Economic factors have relevance to load demand in terms of economic perspective such as a rate of population growth or activation of economies [7, 8]. Also, weather factors (temperature, dew point, humidity, etc.) and time factors (season, holiday, week pattern) are closely related with short term load forecasting [9].

Economic factors are much more difficult to apply for load forecasting model because of complicated statistical methods which need a lot of time and efforts. So, we choose the average growth rate of the load demand which can be easily reflect a rate of economic growth and population [1].

Time and weather factors are selected from the past 3 years data between 2010 and 2012. The time factors are selected from the weekly Toad demand patterns and weather factors are picked from correlation among the weather elements [10]. In order to measure a correlation, we used the person correlation coefficient/method and results can be shown as Table 1 and Table 2 .

Table 1. Correlation coefficient in summer

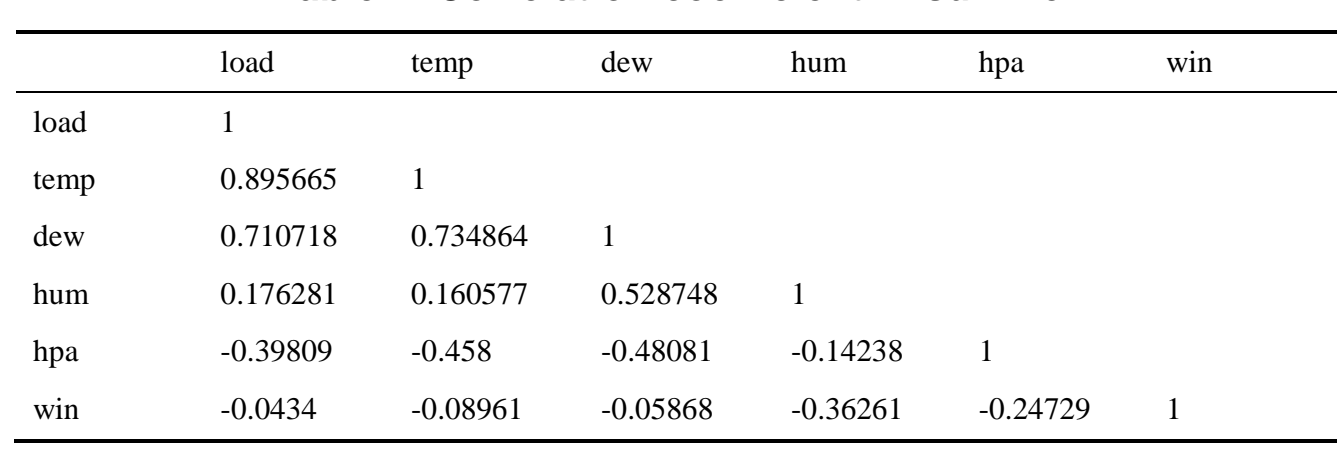

Table 2. Correlation coefficient in winter

\begin{tabular}{lllllll}
\hline & temp & dew & hum & hpa & win \\
\hline load & & & & & & \\
dew & -0.58172 & 0.856977 & 1 & & & \\
hum & -0.34752 & 0.461009 & 0.765228 & 1 & & \\
hpa & 0.090318 & -0.15689 & -0.17703 & -0.07288 & 1 & \\
win & 0.175425 & -0.11674 & -0.2122 & -0.40506 & -0.33922 & 1 \\
\hline
\end{tabular}

Table 1 and Table 2 show the correlation coefficients between historical load demand and each weather variable. The correlation between temperature and historical load for the summer season has value 0.895665 and the next largest value is the dew point which has value 0.710718. Also, in the winter season, the correlation between temperature and historical load is -0.6617 as the most correlated parameter and as the second, dew point is 0.58172 . In the summer season, the load demand more strongly 
depends on the temperature than the winter season. Other weather factors are negligible on the load demand because it has meaningless correlation coefficient.

$\operatorname{Load}_{\text {input }}=\mathrm{L}(\mathrm{d}-1, \mathrm{t})+\mathrm{L}(\mathrm{d}-2, \mathrm{t})+\mathrm{L}(\mathrm{d}-7, \mathrm{t})$

The input load data is consisted of hourly data of three days which are one day before, two days before and one week before the day. Equation (7) denotes the input load variable Load $_{\text {input }}$, $\mathrm{d}$ is a day, and $\mathrm{t}$ is an hour.

\section{Temperature Weight Generation}

In order to improve the accuracy of short term load forecasting, we use the weight value of the temperature and dew point in every hours. The weight value of temperature is composed of two parts which are the Polynomial Regression curve and the variation of the weather elements data. Dew point weight value used to adjust the bias of the weather weight that is related to load demand and temperature. Load demand has closely related to the temperature and dew point Figure 1 shows the relationship among the weather elements which are the load demand, temperature and dew point.

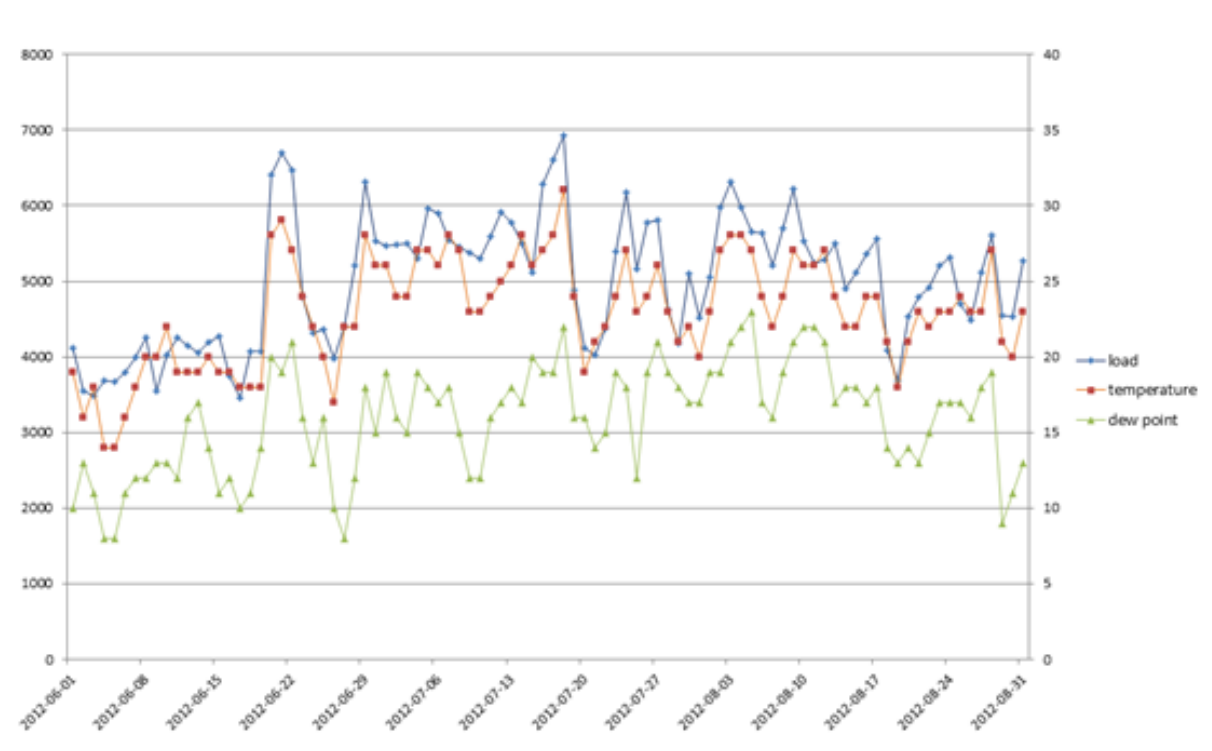

Igure 1. Relationship among the weather elements

The load demand is changed dramatically when the temperature and dew point are raised in the same time. However, the load demand shows the less change when the temperature is raised while the dew point is descended or the temperature is descended while the dew point is raised. Table 3 shows the load demand changing with the temperature and dew point fluctuation.

Table 3. load demand changing with temperature and dew point fluctuation

\begin{tabular}{|l||l|l|l|l|}
\hline Temperature & Increase & Decrease & Decrease \\
\hline Dew point & Increase & Decrease & Increase & $\begin{array}{l}\text { Sensitive } \\
\text { decrease }\end{array}$ \\
\hline Load demand & Sensitive increase & $\begin{array}{l}\text { Insensitive } \\
\text { increase }\end{array}$ & $\begin{array}{l}\text { Insecrease } \\
\text { decrive }\end{array}$ & \\
\hline
\end{tabular}



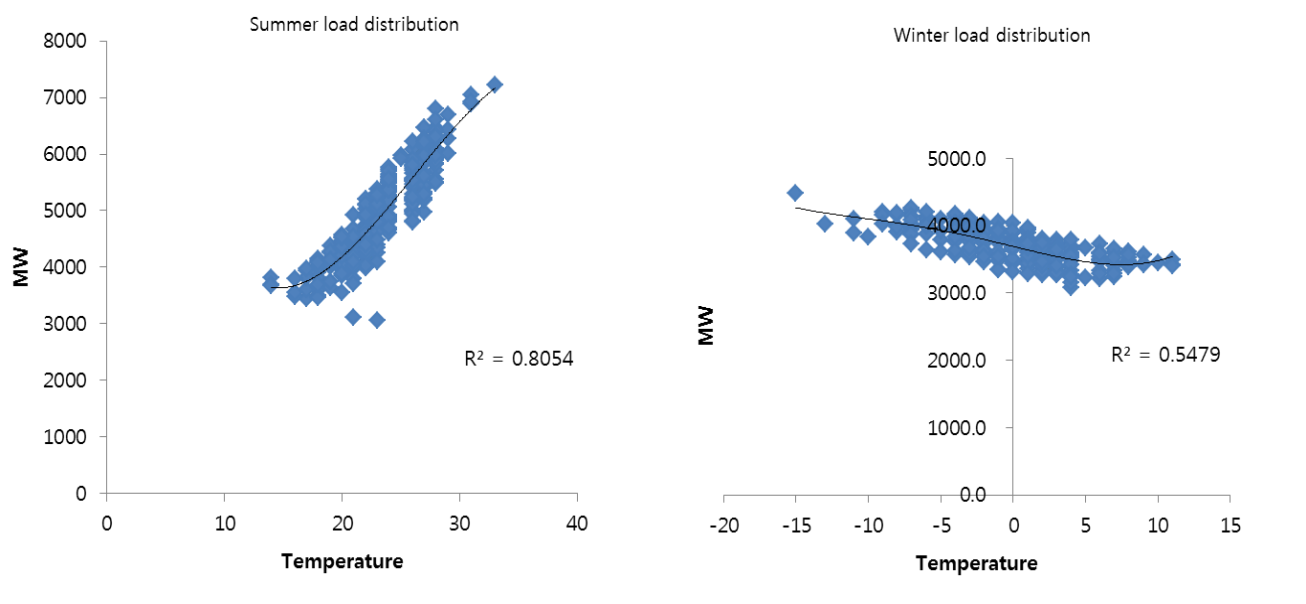

Figure 2. Summer and winter load distributions

Linear regression equations of the electricity load demand are representing the temperature response in the summer and winter seasons. Figure 2. shows the linear regression model of the load demand which is corfetated with temperature. The regression equations are given by:

$Y_{\text {sum }}=-0.6569 \mathrm{X}^{3}+51.29 \mathrm{X}^{2}-10774 \mathrm{X}+10478$
$Y_{\text {win }}=0.0101 \mathrm{x}^{4}+0.2103 \mathrm{x}^{3}-0.0213 \mathrm{x}^{2}-52.009 \mathrm{x}+3690.2$

The equation $Y_{\text {sum }}$ represents the summer regression and the equation $Y_{\text {win }}$ represents the winter regression. In addition, variation of weather factors is measured by the equation (10) and (11). $\Delta T_{i}$ is the variance between one day ahead forecast temperature and present temperature (D) is the variance of dew point which is between one day ahead forecast dew poinfand present dew point.

$$
\begin{aligned}
& \Delta \mathrm{T}_{\mathrm{i}}=\mathrm{T}_{\text {present }}-\mathrm{T}_{\text {before }} \\
& \Delta \mathrm{D}_{\mathrm{i}}=\mathrm{D}_{\text {present }} \mathrm{D}_{\text {before }}
\end{aligned}
$$

The weather weight $\left(\mathrm{W}_{\mathrm{i}}\right)$ is calculated under condition of the Table 3. If $\Delta \mathrm{T}_{\mathrm{i}}$ is larger than 0 , the temperature is increased. In this situation, the weight increase variance is adjusted by the dew point variance $\Delta \mathrm{D}_{\mathrm{i}}$. In the other hand, if $\Delta \mathrm{T}_{\mathrm{i}}$ is less than 0 , the weight decrease variation is adjusted by the dew point variance $\Delta \mathrm{D}_{\mathrm{i}}$.

$$
\mathrm{W}_{\mathrm{i}}=\Delta \mathrm{T}_{\mathrm{i}}+\theta
$$

Where, $\theta$ is the bias of the weather weight

In the summer, if the temperature weight $\left(\mathrm{W}_{\mathrm{i}}\right)$ is increased, the weight value should 
be increased. On the contrary, if $\mathrm{W}_{\mathrm{i}}$ is increased in the winter season, it lead to decrease the weight value because increased temperature reduces the heating load demand. The temperature weight is applied to the proposed model using the equation (13).

If season $==$ summer

$\mathrm{W}_{\mathrm{i}}=\mathrm{Y}_{\text {sum }}+\mathrm{W}_{\mathrm{i}}$

Else If season $==$ winter

$\mathrm{W}_{\mathrm{i}}=\mathrm{Y}_{\mathrm{win}}-\mathrm{W}_{\mathrm{i}}$

The weather weight $\left(\mathrm{W}_{\mathrm{i}}\right)$ is added to the load prediction data (equation (14)). $\mathrm{L}_{\mathrm{i}}$ is the load demand prediction data which is calculated by BPLaldorithm.

$\mathrm{L}_{\mathrm{i}}=\mathrm{L}_{\mathrm{i}}+\left(\mathrm{L}_{\mathrm{i}} \times \mathrm{W}_{\mathrm{i}}\right)$

\section{Experiments and Results}

The proposed model derived the input variables from the historical hourly load demand dataset of the U.S. State of Connecticut during the years 2010 2012 and it is tested on the summer and winter seasons $2012 \mathrm{w}$,ith the actual load and weather data. To implement the proposed model, we use the Datlab 7.12.0. The hourly load demand and weather data was stored in Ky SQL dâabase which is retrieved by SQL query.

In order to evaluate the performance of the load forecasting model, the mean absolute percentage error (MAPE) [11, 12] is considered to measure the accuracy of the load forecast performance between the actual load data and the forecasted load data. The MAPE is definedas follows?

$$
\text { MAPE }=\frac{1}{N} \sum_{n=1}^{n}\left|\frac{Y_{i}-X X 100}{X_{1}}\right| \times 10
$$

Where, $\mathrm{Y}_{\mathrm{i}}$ is the actual load data, and $\mathrm{X}_{\mathrm{i}}$ is the forecasted load data.

Figure 3 and Figure 4 show the experimental results of the one day ahead load predietion in the summer and winter season.

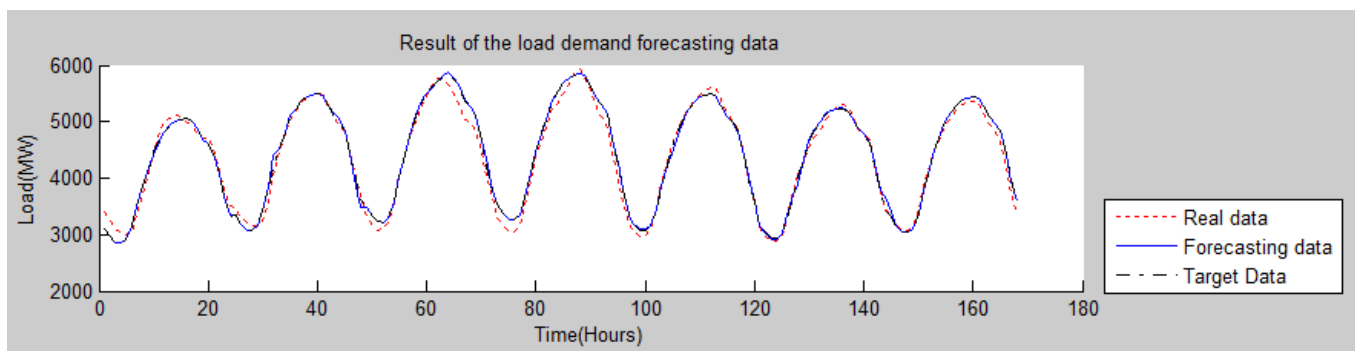

Figure 3. Load forecasting result of the summer season form July $9^{\text {th }}$ to July $15^{\text {th }}, 2012$ 


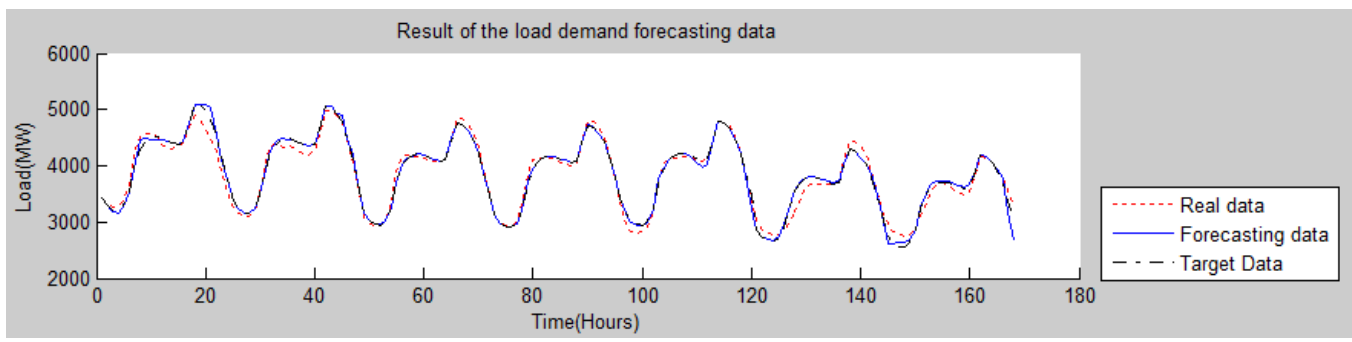

Figure 4. Load forecasting result of the winter season from February $17^{\text {th }}$ to February $23^{\text {th }}, 2012$

Table 4. The result of the MAPE with weather weight

\begin{tabular}{|c|c|c|c|c|}
\hline & \multicolumn{2}{|l|}{ Summer } & Winter & \\
\hline Hours & excluding & including & excluding & including \\
\hline $0 \sim 24 h$ & 9.2490 & 3.3786 & $6.8673 y$ & 3.6459 \\
\hline $24 \sim 48 h$ & 8.8202 & 2.3989 & 16.7048 & 2.2713 \\
\hline $48 \sim 72 h$ & 13.1150 & 3.3360 & $7 \longdiv { 9 9 7 1 }$ & 1.5920 \\
\hline $72 \sim 96 h$ & 16.0661 & 3.9576 & 5.0664 & 1.3154 \\
\hline $96 \sim 120 \mathrm{~h}$ & 5.2823 & 1.7770 & 6.3404 & 1.9196 \\
\hline $120 \sim 144 h$ & 9.2400 & 1.6175 & 7.70830 & 3.7838 \\
\hline $144 \sim 168 \mathrm{~h}$ & 19.6818 & 2.2179 & 7.8262 & 4.1012 \\
\hline Average & 11.6363 & 2,6691 & 8.3586 & 2.6613 \\
\hline
\end{tabular}

Table 2 presents the result of MAPE applied the weather weights for 7 days. In the summer, applying weather weight provides better performance than winter season because the temperature and dew point have more effect on summer. Table 1 and Table 2 indicate that the corretation coefficient of summer temperature and the dew point have higher number than winter season. It means that using the composited weather weight brings out more accuracy forecasting in summer.

\section{Conclusions}

The load demand forecasting accuracy is the important factor to reduce the cost of generating electricity in the electricity market. BPEL algorithm is being widely used for load demand forecasting. In order to improve the accurate forecasting, we used not only weather factors but also seasonal approach. For recognizing the significant weather factors, the proposed model used the correlation coefficient. Temperature and dew point were selected by the result of the correlation analysis. The temperature and dew point interact to adjust the weather weight size, and the weather weight is used to determine the load demand prediction. Summer and winter season have a different pattern of the load demand. Thus, the weather weight differently applied to each season which has season's own pattern of the electric consumption. This paper proposed the hourly load demand forecast of a day ahead using BPL algorithm with weather weight. The simulation on the actual load demand has shown the improvement of load forecasting performance in both summer and winter season. In summer season, the error percentage has been reduced about 77\%, and in winter season, the error percentage has been reduced about $68 \%$. 


\section{Acknowledgements}

This research was supported by a grant (11 High-tech Urban G07) from High-tech Urban Development Program funded by Ministry of Land, Infrastructure and Transport of Korean government. This research was also supported by a 2013 Research Grant from Sangmyung University.

\section{References}

[1] Bureau of economic analysis, U.S. Department of commerce (2013), http://www.bea.gov.

[2] M. Buhari and S. S. Adamu, "Short-Term Load Forecasting Using Artificial Neural Network", Proceedings of the International MultiConference of Engineers and Computer Scientists, vol. 1, (2012), pp. 806-811. ${ }^{\bullet}$

[3] F. Mosalman, A. Mosalman, H. M. Yazdi and M. M. Yazdi, "One day-ahead load forecasting by artificial neural network", Scientific Research and Essays, vol. 6, (2011), pp. 2795-2799.

[4] G. G. Che, T. A. Chiang and Z. H. Che, "Feed-forward neural networks training: a comparíson between genetic algorithm and back-propagation learning algorithm", Internatiohal Journal of Innovative Computing, Information and Control, vol. 7, (2011), pp. 5839-5850.

[5] R. Rojas, "Neural Networks", Springer-Verlag, Berlin, (1996)

[6] Z. H. Osman, M. L. Awad and T. K. Mahmoud, "Neural network based approach for short-term load forecasting", Power Systems Conference and Exposition (PSCE), IEEE ptess, Seattle, (2009), pp. 1-8.

[7] G. Gross and F. D. Galiana, "Short-term load forecasting, Proceedings of the IEEE, vol. 5, no. 12, (1987), pp. 1558-1573.

[8] PJM, Manual 19: Load Forecasting and Analysis Date. Prepared by Resource Adequacy Planning, (2013).

[9] W. Hongbin and C. Wei-li, "Load Forecasting For Electrical Poyter System Based On BP Neural Network", In: Education Technology and Computer Science, (2009), Pp. 702-705.

[10] K. H. Kim, J. K. Park and K. K. Hyang, "A Hybrid Short-term Load Forecasting Model using Artificial Neural Networks and Fuzzy Expert Systems`(in Korean)", The Transactions of the Korean Institute of Electrical Engineers, vol. 43, nQ. 12, (1994), pp. 2002-2009.

[11] D. Ortiz-Arroyo, M. K. Skov and Q. Huym, "Accurate Electricity Load Forecasting with Artificial Neural Networks", Proceedings of the Internatignal Conference on Computational Intelligence for Modeling, Control and Automation and International Conference on Intelligent Agents, Web Technologies and Internet Commerce, IEEE Press, Vienna, (2005), pp. 94-99.

[12] W. Charytoniuk and M. S Cherp, "Neural network design for short-term load forecasting", Proceedings of the International Conference on Electric Utility Deregulation and Restructuring and Power Technologies, (2000), pp. 554-561.

[13] I. Aquino, C. Perez, J. KChavez and S. Oporto, "Daily Load Forecasting Using Quick Propagation Neural Network with a Specjal Holiday Encoding”, Proceedings of the International Joint Conference on Neural Networks, Celebrating 20 years of neural networks, Florida, (2007), pp. 1935-1940.

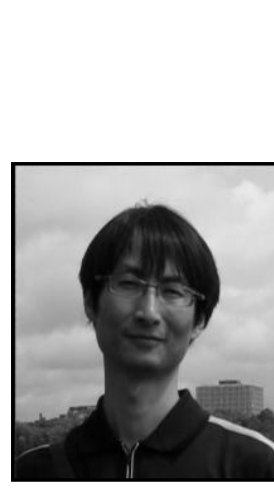

\section{Authors}

\section{Kwon}

He received his MS degree in computer science from Sangmyung University, Korea, and also his MS degree in computer science at Towson University, USA. He is currently a software engineer. His research interests are in the areas of Intelligent Agent, Neural Networks, Expert System, Web service modeling and Computing, Service Oriented Architecture, Voice over IP, Mobile communication, E-learning, ERP. 


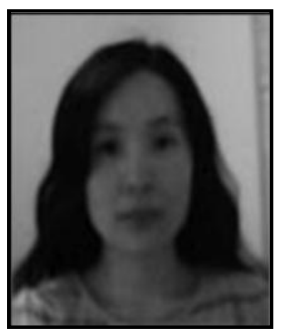

\section{Kim}

She received her MS degree in computer science from Sangmyung University, Korea, She is currently a student in Information Technology at Towson University, USA. Her research interests are in the areas of Intelligent Agent, Neural Networks, Expert System, Multimedia File System, Multimedia Application, E-learning, and Digital Watermarking.

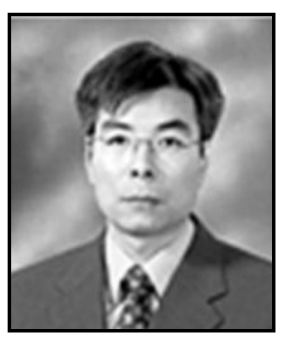

\section{Hong}

He received his M.S. degree and Ph.D. degree in Compute Science at New Jersey Institute of Technology, USA and Unixe sity of MissouriRolla, USA, respectively. He was a sentior researeth in Electronic and Telecommunications Research Institate, Korea, He is currently professor of Computer Science Department at Sangmyung University, Seoul, Korea. His research interests Include Parallel and Distributed System, Optimization Algorithm, Maltimedia Application, and Intelligent Agent, Neural Networks, ExpertSystem.

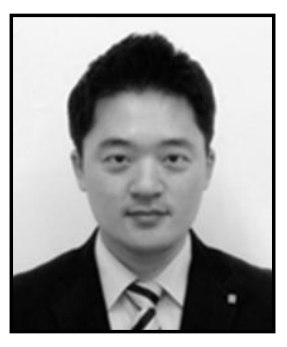

\section{S. Cho}

$\mathrm{He}$ received the MS degree and $\mathrm{PhD}$ degree in Department of Electrical Engineering at Korea University, Seoul, Korea. He is currently a professor in Department of Energy Grid at Sangmyung University, Seoul Korea. His research interests are in the areas of Power Quality Analysis, Power Signal Processing, Smart-Grid and Renewable Energy, Numerical Análysis, Measurement and Maintenance Methodology, PQ State Estimation, Neural Networks.

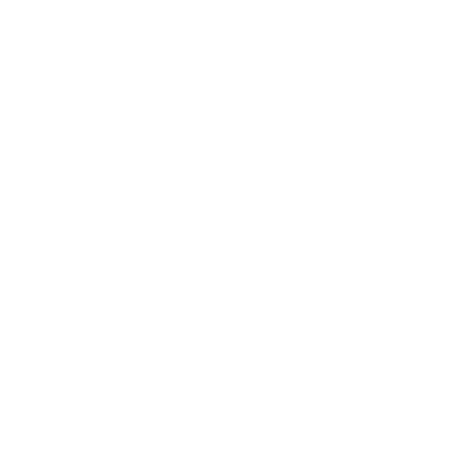


International Journal of Multimedia and Ubiquitous Engineering Vol.9, No.1 (2014)

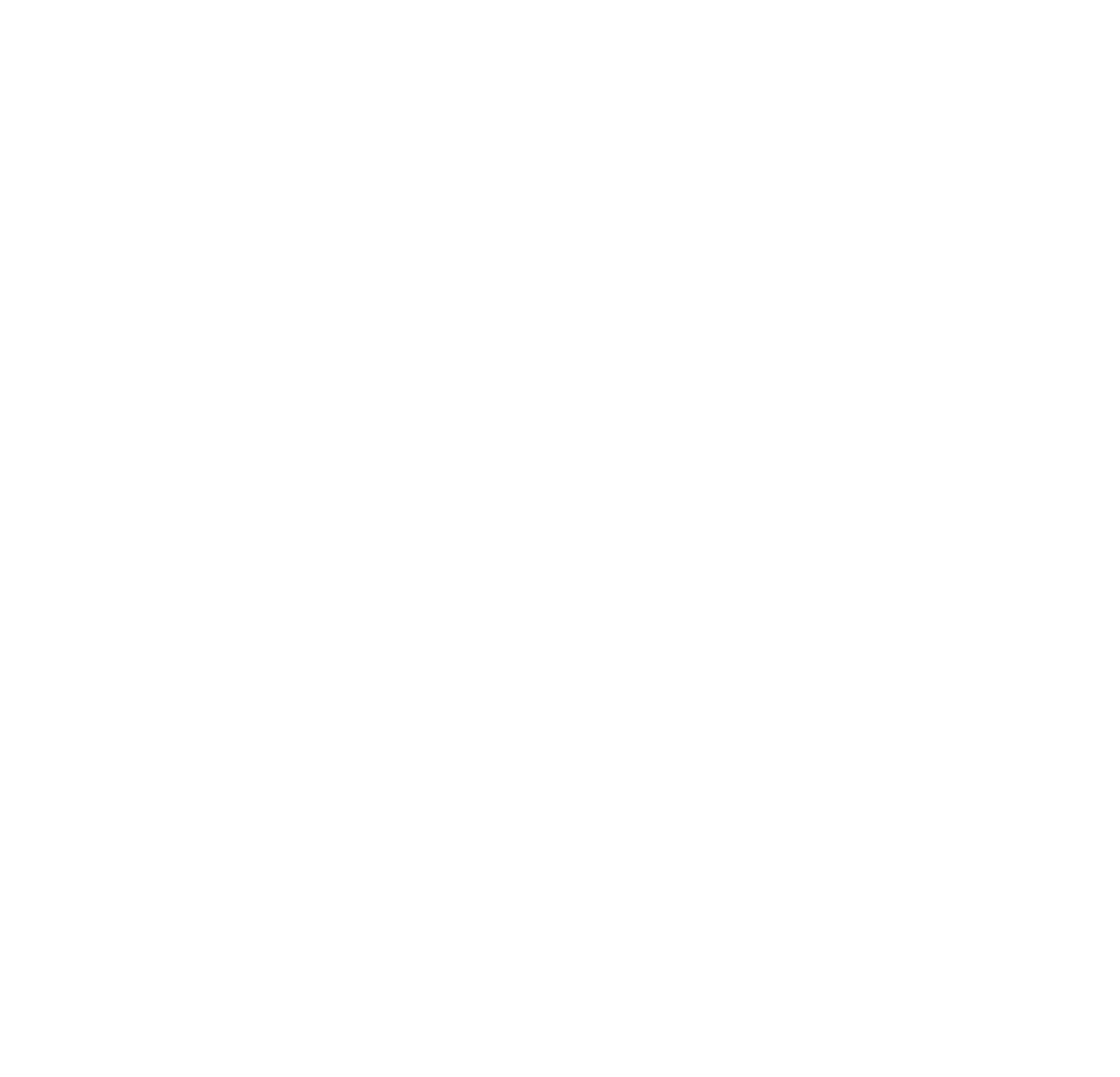

